\title{
Early or Delayed Reversal of Temporary Ileostomy after Typhoid Perforation: A Comparative Study at Tertiary Care Hospital
}

Shiraz Shaikh, Zameer Hussain Laghari, Qamber Ali Laghari, Shahnawaz Abro, Nawaz Ali Dal

\begin{abstract}
OBJECTIVE: To compare the effectiveness of early reversal versus delayed reversal of temporary ileostomy after typhoid perforation in terms of morbidity and mortality at Liaquat University of Medical and Health Sciences.

METHODOLOGY: This prospective comparative study was conducted in department of surgery, Liaquat University of Medical and Health Sciences, Jamshoro from April 2018 to March 2019. Patients admitted in the surgical unit, underwent temporary ileostomy after typhoid perforation either of gender were enrolled. Patients were equally divided in two groups via lottery method. Patients of group I underwent early reversal of temporary ileostomy and patients of group II underwent delayed reversal of temporary ileostomy. Effectiveness was assessed in terms of postoperative complication and mortality including hospital stay. Data was collected through self-made proforma and analyzed by SPSS version 20.

RESULTS: Total 78 patients were enrolled and their mean age was $28.2 \pm 10.3$ years of early reversal group and $33.5 \pm 6.3$ of group late reversal group. Males were most common in both groups i.e. $67.0 \%$ in group I and $64.0 \%$ in group II. According to the postoperative complications; skin excoriation, parastomal hernia, wound infection and intra-abdominal collection were insignificant among both groups. Prolonged hospital stay was higher in patients of late reversal group as compared to early reversal group, $p$-value 0.004 .

CONCLUSION: It was concluded that early reversal of temporary ileostomy is feasible and safe, though by early reversal of temporary would yield economic and administrative benefits to the department and personal benefits for patients to live a better quality of life much earlier.
\end{abstract}

KEYWORDS: Early reversal, late reversal, lleostomy

This article may be cited as: Shaikh S, Laghari ZH, Laghari QA, Abro S, Dal NA. Early or Delayed Reversal of Temporary lleostomy after Typhoid Perforation: A Comparative Study at Tertiary Care Hospital. J Liaquat Uni Med Health Sci. 2020;19(02):78-81. doi: 10.22442/jlumhs.201920666

\section{INTRODUCTION}

lleal perforation is a frequently encountering and formidable surgical emergency in developing countries $^{1}$. Typhoid fever is common and reported as the predominant cause of non-traumatic ileal perforation ${ }^{2}$. Typhoid fever is endemic in few parts of Pakistan, especially in Sindh, with most of the patients were quinolone resistant and presented with ileal perforation. These patients usually having severe intraperitoneal contamination, so ileostomy is the only resort of such patients. Other causes of ileal perforation include malignancy, tuberculosis, crohn's disease etc ${ }^{3}$. lleal perforation due to typhoid fever has been observed with the remarkable difference in high and low income countries that are $0.8 \%$ to $18 \%$ respectively ${ }^{4}$. Ileal perforation secondary to typhoid is a alarming condition and need urgent surgical intervention. Ileostomy as a treatment modality carries lower mortality rate due to the early start of enteral feeding and nutritional built up higher rate of morbidity due to increased hospital stay ${ }^{4-5}$. Reversal of a loop stoma can be carried out under local, spinal or general anesthesia by intra-peritoneal or extra-peritoneal closure. The procedure of ileostomy usually performed
8 to 12 -week duration ${ }^{6}$. It is easier to perform if period of at least 12 weeks allowed elapsing between formation of the stoma and reversal so that there is time for edema and inflammatory adhesions to settle ${ }^{5-}$ 7. The quality of life of patient may get affected due to its related complications ${ }^{7}$. There is a great current interest towards the early reverse of intestinal stomas; many of the studies had advocated the new concept of early reverse of intestinal stoma after 4 weeks from its creation $^{8}$. However, a review from a study concluded that closing of temporary stoma can be done within 2 weeks and it did not seem to be associated with an increase in morbidity and mortality ${ }^{5}$. Despite the fact that stoma (ileostomy) reversal is a lifesaving procedure, still it may result in number of major complications ranging from $0 \%$ to $9 \%$ and minor complications from $4 \%$ to $30 \%$ that require reopening of abdomen ${ }^{8-9}$. Early reversal ileostomy is beneficial for patients in terms of improving quality of life as the complications like stoma leakage, irritation of parastomal skin, stoma prolapsed etc. are limited comparison with the late reversal procedure ${ }^{10-11}$. Early reversal ileostomy is also effective in reducing the overall health care cost as well as reduces the 
complaints of post-surgical nausea and vomiting ${ }^{11}$. To the best of our knowledge, no study conducted in Pakistan or in Sindh. Hence this study has been conducted assess the effectiveness of early reversal versus delayed temporary ileostomy after typhoid perforation in terms of morbidity and mortality at LUMHS. On equal or best outcome of early reversal technique, this will be recommended to decrease the economic burden and better early survival.

\section{METHODOLOGY}

Present prospective comparative study was conducted in department of surgery, Liaquat University of Medical and Health Sciences, Jamshoro from April 2018 to March 2019. Study was done after ethical approval of ethical review committee of LUMHS. Patients admitted in the surgical unit in whom the temporary ileostomy was carried out after typhoid perforation according to our unit protocols having age more than 12 years and either of gender were included, those were unfit for anesthesia, diabetes and not agree to participate in the study were excluded from the study. 78 patients were calculated via raosoft software by taking proportion of $(9.2 \%$ of typhoid perforation) with $90 \%$ confidential level and $5 \%$ margin error. Patients were divided in two groups group I and II via lottery method. Patients of group I underwent of early reversal and patients of group II underwent delayed reversal. Informed consent was taken from each patient prior the study and also informed regarding the purpose, method and involvement of any risk during the study as well as they were given freedom to leave the study at any point. lleostomy reversal (stoma closure) procedure was performed by senior general surgeon minimum experience more than 5 years. Patients were followed for 15 days. All the data regarding demographic characteristics including post-operative complication as; wound infection, intra-abdominal collections, laparotomy, leak at anastomotic site and medical complications like pneumonia, urinary tract infection, deep venous thrombosis and other stoma were recorded. Data was analyzed by using SPSS version 20. Mean and standard were computed for numerical variables. Frequency and percentage were computed for categorical variables. Chi-square test was applied and a $p$-value $<0.05$ was considered as significant.

\section{RESULTS}

Total 78 patients were studied; their mean age was $28.2 \pm 10.3$ years early reversal group and $33.5 \pm 6.3$ of group late reversal group. Out of all study participants $38(48.7 \%)$ had age group of $16-25$ years, $25(32.05 \%)$ were with age group of 26-35 years and $15(19.23 \%)$ were between $36-45$ years. Males were most common in both groups i.e. $67.0 \%$ in group I and $64.0 \%$ in group II, while females were $33 \%$ in group I and $34 \%$ in group II. Findings regarding age and gender were statistically insignificant. $28 \%$ patients were smokers of group I and 43.5\% smokers were in group II. According to the presenting symptoms abdominal pain, nausea/vomiting and fever were most common in both groups and statistically insignificant p-value 0.567 . Most of the cases of both groups had operating time $<120$ minutes as; $64 \%$ of group I and $54 \%$ of group II, p-value 0.443 . Bleeding during the surgery was $33 \%$ in group I and $25.5 \%$ in group II. Table I.

According to the postoperative complications skin excoriation, parastomal hernia, wound infection and intra-abdominal collection were significantly lower in group I as compared to group II. Prolonged hospital stay was higher in patients of group II as compared to group I, p-value 0.004.Table II.

\section{TABLE I: COMPARISON OF GENERAL CHARACTERISTICS BETWEEN BOTH STUDY GROUPS $(n=78)$}

\begin{tabular}{|c|c|c|c|}
\hline Variables & $\begin{array}{c}\text { Early Closure } \\
\text { group } \\
n=39\end{array}$ & $\begin{array}{l}\text { Late closure } \\
\text { group } \\
n=39\end{array}$ & P-value \\
\hline $\begin{array}{l}\text { Age Group (years) } \\
16-25 \\
26-35 \\
36-45\end{array}$ & $\begin{array}{l}21(54) \\
11(28) \\
07(18)\end{array}$ & $\begin{array}{l}17(43.5) \\
14(36.0) \\
08(20.5)\end{array}$ & 0.655 \\
\hline $\begin{array}{l}\text { Gender } \\
\text { Male } \\
\text { Female }\end{array}$ & $\begin{array}{l}26(67) \\
13(33)\end{array}$ & $\begin{array}{l}25(64) \\
15(38)\end{array}$ & 0.812 \\
\hline $\begin{array}{l}\text { Smoking History } \\
\text { Yes } \\
\text { No }\end{array}$ & $\begin{array}{l}11(28) \\
28(72)\end{array}$ & $\begin{array}{l}17(43.5) \\
22(56.0)\end{array}$ & 0.157 \\
\hline $\begin{array}{l}\text { Presenting } \\
\text { symptoms } \\
\text { Abdominal Pain } \\
\text { Nausea/ Vomiting } \\
\text { Fever } \\
\text { Constipation } \\
\text { Diarrhea } \\
\text { Shock }\end{array}$ & $\begin{array}{l}36(92.0) \\
28(72.0) \\
21(54.0) \\
08(20.5) \\
11(28.0) \\
20(51.2)\end{array}$ & $\begin{array}{l}34(87.0) \\
23(59.0) \\
25(64.0) \\
07(18.0) \\
14(36.0) \\
23(59.0)\end{array}$ & 0.567 \\
\hline $\begin{array}{l}\text { Operating Time } \\
<120 \text { minutes } \\
120-240 \text { minutes } \\
>240 \text { minutes }\end{array}$ & $\begin{array}{c}25(64) \\
08(20.5) \\
06(15.5)\end{array}$ & $\begin{array}{l}21(54) \\
13(33) \\
05(13)\end{array}$ & 0.443 \\
\hline $\begin{array}{l}\text { Bleeding during } \\
\text { surgery } \\
\text { Yes } \\
\text { No }\end{array}$ & $\begin{array}{l}13(33) \\
26(67)\end{array}$ & $\begin{array}{l}08(20.5) \\
31(79.5)\end{array}$ & 0.202 \\
\hline
\end{tabular}

\section{DISCUSSION}

Reversal of ileostomy is the procedure performed to rejoin or reconnect the loop or end of ileum for restoration of gut continuity, attached previously with the abdominal skin to form stoma for the management of intestinal leaks following index surgery. In this study early reversal showed good outcome equal to late reversal group mostly in terms of postoperative 
TABLE II: COMPARISON OF POST-OPERATIVE COMPLICATIONS AND HOSPITAL STAY IN BOTH GROUPS $(n=78)$

\begin{tabular}{lccc}
\hline \multicolumn{1}{c}{ Variables } & $\begin{array}{c}\text { Early } \\
\text { reversal } \\
\text { group(n=39) }\end{array}$ & $\begin{array}{c}\text { Late } \\
\text { reversal } \\
\text { group(n=39) }\end{array}$ & P-Value \\
\hline Complications & & & \\
Skin Excoriation & 3 & 6 & \\
Parastomal Hernia & 0 & 4 & 0.653 \\
Wound Infection & 4 & 3 & \\
Retraction & 0 & 3 & \\
\hline Urinary Tract Infection & 2 & 3 & \\
Intra-abdominal & 2 & 4 & \\
collection & 1 & 2 & \\
Anastomotic Leak & 2 & 3 & \\
Electrolyte Imbalance & 2 & 14 & \\
Hospital stay & 25 & 19 & \\
<10 days & 09 & 06 & \\
11-20 days & 05 & & \\
$>$ 20 days & & & \\
\hline
\end{tabular}

infection, as we found wound infection was 4 patients of early reversal group and 3 patients of late reversal group which was statistically insignificant. While in the study of Sarawgi M $2017^{16}$ reported that wound infection was the most frequently encountered postoperative complication (20\%) in early group. These findings are consistent with the findings of Alves $A$ $2008^{17}$, who also observed that the surgical site infection was more common in patients that underwent early reversal than those that underwent late reversal ${ }^{17}$. In this study no mortality was observed during hospital stays, which was similar to the findings of Alves A $2008^{17}$.

In this study, anastomosis leak was found in one patient of early reversal group and in 2 patients of late reversal group, which is statistically insignificant. Sarawgi M 2017 $7^{16}$ reported that in late closure group two patients developed anastomotic leak requiring re-laparotomy and re-stoma formation.

In this study, hospital stay was significantly shorten in early reversal groups patients in contrast to late reversal group's patients $p$-value 0.004 . Similarly Menegaux F $2002^{18}$ reported that the median length of hospital stay of their patients was significantly shorter in early closure group compared with the conventional closure group. Studies revealed that early closure of ileostomy is not only feasible but also reduces the morbidity and ultimately improves the quality of life ${ }^{8-10}$. In one study, Omundsen M $2012^{15}$ reported that in their study there was $23 \%$ increase in complications in early reversal group. In another recent study of Abdalla S $2018^{19}$ also found comparable findings as hospital length of stay and average number of postoperative complications following circumstomal loop ileostomy closure were significantly lower in the early than in the late closure group. In this study intra-operative blood loss and a similar number of conversions to laparotomy in both groups confirm the technical feasibility of early stoma closure and shows that early closure can be undertaken without additional operative morbidity. Similar findings were recorded by a previous study from France ${ }^{16}$.

In this study mean age was $28.2 \pm 10.3$ years early reversal group and $33.5 \pm 6.3$ of group late reversal group. While in the study of Abdalla S $2018^{19}$ stated that mean age of early group patients was 68.6 years and 71.6 years of late reversal group, while gender distribution was similar to this study. With the strengths, present study had a few limitations. First of all this study was conducted in one public sector tertiary care centre so we don't limited number of patients to study. Secondly, we don't have any specific cut-off for the early reversal of ileostomy despite that it was taken as range of 14 to 28 days. Total cost incurred was only analyzed for the ileostomy (stoma) care i.e. only cost of stoma bags etc was analyzed in our study. Whereas, the total healthcare cost of patient couldn't be analyzed as the study was carried out in a public sector hospital where there is no charge or treatment cost applied. Furthermore, we had done assessment of quality of life of patients after temporary ileostomy subjectively but not objectively in this study.

\section{CONCLUSION}

It was concluded that early reversal of temporary ileostomy is feasible and safe. By early reversal of temporary would yield economic and administrative benefits to the department and personal benefits for patients. Complications like risk of bleeding, anastomotic leak and other medical as well as surgical complications with early reversal method is very limited comparison to the late reversal of temporary ileostomy.

Ethical permission: Liaquat University of Medical \& Health Sciences ERC approval letter No. LUMHS/ REC/-658, dated: 19-03-2018.

Conflict of Interest: There is no conflict of interest.

Funding: There was no any funding agency.

\section{REFERENCES}

1. Verma H, Dev K, Pandey S, Gurawalia J, Marwah $\mathrm{S}$. Temporary loop versus end ileostomy for faecal diversion in ileal perforation: a case matched study. Sri Lanka J Surg. 2016; 34(1): 1-6. doi:10.4038/sljs.v34i1.8233.

2. Verma H, Pandey S, Sheoran KD, Marwah S. Surgical audit of patients with ileal perforations requiring ileostomy in a Tertiary Care Hospital in India. Surgery research and practice. 2015; 2015: 351548. 10.1155/2015/351548.

3. Robertson JP, Puckett J, Vather R, Jaung R, Bissett I. Early closure of temporary loop ileostomies: A systematic review. Ostomy Wound 
Manag. 2015; 61(5): 50-7.

4. Atamanalp SS, Aydinli B, Ozturk G, Oren D, Basoglu M, Yildirgan Ml. Typhoid intestinal perforations: twenty-six year experience. World $\mathrm{J}$ Surg. 2007; 31(9): 1883-8. doi: 10.1007/s00268007-9141-0.

5. Rubio-Perez I, Leon $M$, Pastor D, Diaz Dominguez J, Cantero R. Increased postoperative complications after protective ileostomy closure delay: An institutional study. World J Gastrointest Surg. 2014; 6(9): 169-74. doi: 10.4240/wjgs.v6.i 9.169.

6. Mala T, Nesbakken A. Morbidity related to the use of a protective stoma in anterior resection for rectal cancer. Colorectal Dis. 2008; 10(8): 785-8. doi: 10.1111/j.1463-1318.2007.01456.x.

7. Silva MA, Ratnayake G, Deen KI. Quality of life of stoma patients: Temporary ileostomy versus colostomy. World J Surg. 2003; 27(4): 421-4. doi: 10.1007/s00268-002-6699-4.

8. Krand O, Yalti T, Berber I, Tellioglu G. Early vs. delayed closure of temporary covering ileostomy: A prospective study. Hepatogastroenterology. 2008; 55(81): 142-5.

9. Khan MA, Imran $A$, Nawaz $H$, Arif A, Ullah A. Frequency of surgical site infection following owing intestinal stoma. Khyber J Med Sci. 2013; 6 (1): 102-7.

10. Hindenburg T, Rosenberg J. Closing a temporary ileostomy within two weeks. Dan Med Bull. 2010; 57(6): A4157.

11. Rajaretnam N, Lieske B. lleostomy. Stat Pearls [Internet]. Treasure Island (FL): Stat Pearls Publishing; 2018.

12. Clavien PA, Barkun J, de Oliveira ML, Vauthey JN, Dindo D, Schulick RD, et al. The ClavienDindo classification of surgical complications: Five -year experience. Ann Surg. 2009; 250(2): 187-

AUTHOR AFFILIATION:

Dr. Shiraz Shaikh (Corresponding Author) Assistant Professor, Department of Surgery Liaquat University of Medical \& Health Sciences (LUMHS), Jamshoro, Sindh-Pakistan. Email: shiraz_shaikh2003@hotmail.com

\section{Dr. Zameer Hussain Laghari}

Associate Professor, Department of Surgery LUMHS, Jamshoro, Sindh-Pakistan.
96. doi: 10.1097/SLA.0b013e3181b13ca2.

13. Aaronson NK, Ahmedzai S, Bergman B, Bullinger $M$, Cull A, Duez NJ, et al. The European Organization for Research and Treatment of Cancer QLQ-C30: A quality-of-life instrument for use in international clinical trials in oncology. J Natl Cancer Inst. 1993; 85(5): 365-76. doi: 10.1093/jnci/85.5.365.

14. Gujral S, Conroy T, Fleissner C, Sezer O, King $\mathrm{PM}$, Avery KN, et al. Assessing quality of life in patients with colorectal cancer: An update of the EORTC quality of life questionnaire. Eur J Cancer. 2007; 43(10): 1564-73. doi: 10.1016/j. ejca.2007.04.005.

15. Omundsen $M$, Hayes $J$, Collinson R, Merrie A, Parry B, Bissett I. Early ileostomy closure: Is there a downside? ANZ J Surg. 2012; 82(5): 352-4. doi: 10.1111/j.1445-2197.2012.06033.x.

16. Sarawgi M, Singh SK, Tiwary AK, Kumar A. Early Vs Delayed Loop lleostomy Closure: A Comparative Study. IOSR J Dent Med Sci. 2017; 16(7): 08-13.

17. Alves A, Panis $Y$, Lelong B, Dousset B, Benoist S, Vicaut $\mathrm{E}$. Randomized clinical trial of early versus delayed temporary stoma closure after proctectomy. $\mathrm{Br} \mathrm{J}$ Surg. 2008; 95(60): 693-8. doi: 10.1002/bjs.6212.

18. Menegaux F, Jordi-Galais $P$, Turrin N, Chigot JP. Closure of small bowel stomas on post-operative day 10. Eur J Surg. 2002; 168(12): 713-5. doi: 10.1080/00000000000000008.

19. Abdalla S, Scarpinata R. Early and Late Closure of Loop lleostomies: A Retrospective Comparative Outcomes Analysis. Ostomy Wound Manage. 2018; 64(12): 30-5.

20. Na'aya HU, Eni UE, Chama CM. typhoid perforation in Maiduguri, Nigeria. Annals of African Medicine. 2004; 3(2): 69-72.

\section{Dr. Qamber Ali Laghari}

Assistant Professor, Department of Surgery LUMHS, Jamshoro, Sindh-Pakistan.

Dr. Shahnawaz Abro

Assistant Professor, Department of Surgery LUMHS, Jamshoro, Sindh-Pakistan.

Dr. Nawaz Ali Dal

Assistant Professor, Department of Surgery LUMHS, Jamshoro, Sindh-Pakistan. 